\title{
Risk management in the logistics projects
}

\author{
Tereza Belantová ${ }^{1,}$ Pavel Taraba ${ }^{2}$ \\ ${ }^{1}$ Tomas Bata University in Zlin, Faculty of Management and Economics, Mostní 5139, 76001 Zlín, Czech Republic \\ ${ }^{2}$ Tomas Bata University in Zlin, Faculty of Logistics and Crisis Management, Studentské nám. 1532,68601 \\ Uherské Hradiště, Czech Republic
}

\begin{abstract}
The aim of the research was to find out what approach the companies in the Czech Republic are taking to the risk management process in logistics projects. The article briefly introduces theoretical foundations with an emphasis on risk management. Data collection was conducted through a questionnaire survey in the first quarter of 2019. The conclusion of the questionnaire survey clearly shows that most companies in the Czech Republic implement the risk management process themselves using their employees and do not use external workers. The smaller majority of these companies have a single person and do not have the need to have multiple workers for risk management.
\end{abstract}

\section{Introduction}

Nowadays, businesses are increasingly global, the industrial environment is heavily influenced by uncertainty that can potentially turn into unexpected disruptions, and logistical projects are threatened by all kinds of uncertainties and risks [1]. A typical logistics project consists of many different entities, from material suppliers, manufacturers, distributors, wholesalers to retailers. It is natural, therefore, that in most cases the logistics project only works efficiently and correctly when all project actors are working correctly, i.e. if some subject fails, the logistics project easily collapses and fails to achieve its objectives [2]. As the number of stakeholders involved in the logistics project increases, the likelihood of their failure increases.

If the logistics project is well managed, it can give the organization a sustainable advantage over the competition, because efficient logistics management helps to increase customer satisfaction while maintaining quality of delivery and reducing costs [3-4]. Achieving success in managing a logistics project is conditioned by the ability to plan projects and to implement logistics correctly when planning specific activities. The specifications of each project and its uniqueness make risk an integral part of these projects. The level of this risk varies depending on the type of project, its scope, size of project logistics, behavior, and other factors [5]. Businesses must continually evaluate potential risks and give them the same level of attention as in any other area [6].

The purpose of the risk management process is to protect the integrity of the organization from unfortunate events and their consequences, in order to maximize performance and maximize profits [7-8]. There is no doubt that risk management in the logistics and supply chain, both in academia and industry, is a topical and important issue today that requires solutions [9]. Therefore, one of the most important preconditions for a successful business is integrating the risk management process into business management as an essential part of enterprise competitiveness [10].

Increasing costs and complexity in organizations leads to increasing uncertainties and risks. This results in an increasing implementation of the risk management process to reduce the risk and thereby avoid deviation from the target [11]. By introducing a project risk management process, companies can reduce the negative impact of insecure events and / or reduce the likelihood of these negative events occurring while focusing on capturing opportunities [12]. The project risk management process includes the following activities: project risk identification, project risk analysis, definition and implementation of risk response measures and project risk monitoring [13]. The difference between successful and failed projects lies in the level of use of risk management methods, indicating the importance of the risk management process in projects. The greater the scope of risk management, the better the project results are [14]. These studies point to a positive relationship between project risk management and project success. $\mathrm{Mu}$ et al. [15] conducted an empirical study in China. The result of this study was a positive relationship between risk management strategies and the performance of new product development projects. Research by Salomo et al. [16] confirm the positive impact of risk management on new product development projects. In its study, Project Risk Planning and Objectives Stability throughout the development process had a significant positive impact on the performance of new product development projects. However, Raz, Shenhar, and Dvir [17] suggest that the procedure of risk management are

* Corresponding author: belantova@utb.cz 
still not widely implemented in practice enough, adding that risk management is positively linked to project success when implemented. It should be noted that project risk management is sometimes simply referred to as risk analysis, which is only one part of the process. However, this meaning is very used, so it can be encountered very often [18]. Risk Management is a process of focusing on risk analysis and mitigation using a variety of methods and procedures that eliminate existing or future factors that could increase risk. This is a systematic and repetitive set of interrelated activities designed to cope with potential risks and reduce the likelihood of a risk occurring or reduce the impact of the risk. The purpose of the risk management process is to avoid problems or negative phenomena [10].

\section{Research design and methodology}

For the purposes of this article, a questionnaire survey was conducted with representatives of logistics enterprises and workers of logistics. The aim of the research was to find out what approach the enterprises have to risk management process in the Czech Republic. The questionnaire was sent electronically, specifically by email. The number of questionnaires processed was 28 . The questionnaire was divided into three blocks. The first block is focused on the employee himself, who was asked about the job position and the time he works in the company. The second block of questions was directed at the enterprises. For enterprises, it was monitored whether it was a micro enterprise, a small enterprise, a medium-sized enterprise and a large enterprise, based on the number of employees. Furthermore, according to the scope of the businesses, enterprises were categorized as a regional enterprise, a national enterprise or a multinational enterprise. And the sector in which the enterprise was founded was investigated. The last block of questions focused on the enterprises' risk management process. It was examined whether the risk management process is carried out by only one employee, or the enterprises had a multi-employee department, or whether they were using external personnel. Another of the questions was focused on the specific risks associated with business, the risk management methods that the enterprise uses to eliminate these risks and the amount of money the company spends on eliminating these risk. The last question was to find out what kind of treatment of risk the enterprise prefers.

\section{Results}

A questionnaire survey was conducted for the purposes of this article. The survey was conducted in the Czech Republic. $89.3 \%$ of the surveyed enterprises were national and $10.7 \%$ of the survey respondents were transnational. Another of the company's capabilities was regional, but none of the companies surveyed were regional. Half of respondents belong to the category of medium-sized enterprises. The size of the company was determined by the number of employees, ranging from
51 employees to 250 employees. Other categories included micro enterprises, small enterprises, and large enterprises. There was no enterprise surveyed among micro enterprises. Most companies belong to the wholesale, retail, repair and maintenance of motor vehicles. The sectors were classified by SCEA [19]. Questionnaire surveys that are focused on enterprises are summarized in Table 1.

Table 1. Summary of questions focused on the enterprises.

\begin{tabular}{|l|l|}
\hline \multicolumn{2}{|c|}{ Enterprises size } \\
\hline Small enterprises & $21.4 \%$ \\
\hline Medium-sized enterprise & $50 \%$ \\
\hline Large enterprise Scope of enterprises \\
\hline \multicolumn{2}{|c|}{ Sector of business } \\
\hline National & $28.6 \%$ \\
\hline Transnational & $89.3 \%$ \\
\hline \multicolumn{2}{|c|}{$10.7 \%$} \\
\hline Manufacturing industry & $17.9 \%$ \\
\hline $\begin{array}{l}\text { Wholesale, retail, repair and maintenance } \\
\text { of motor vehicles }\end{array}$ & $35.7 \%$ \\
\hline Transport and storage & $25 \%$ \\
\hline $\begin{array}{l}\text { Accommodation, catering, and } \\
\text { hospitality }\end{array}$ & $10.7 \%$ \\
\hline Other activities & $10.7 \%$ \\
\hline
\end{tabular}

The following figure illustrates the methods used by enterprises. It is clear from the below graph that the FMEA method represents the largest share of the methods operated in the risk management process in Czech enterprises, this method is used in half of all surveyed enterprises. Other methods used in the risk management process are What If Analysis, Check List and Scenario Planning. In addition to these methods, other risk management methods are used in enterprises.

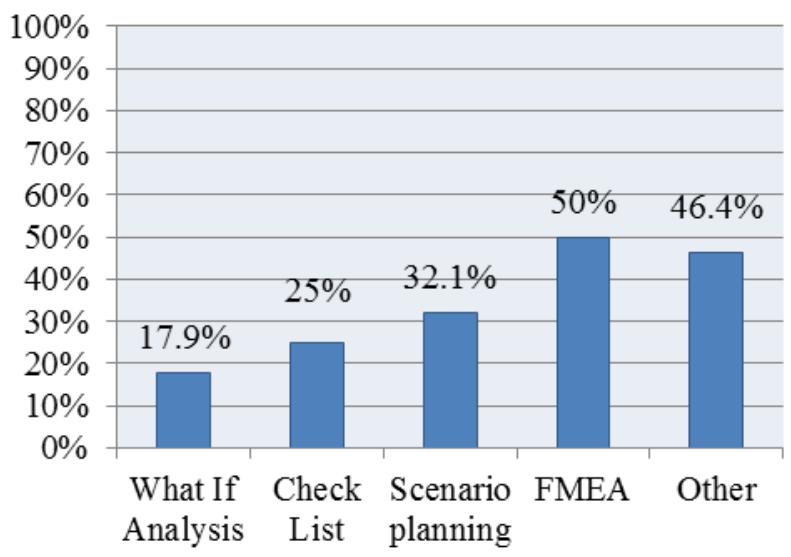

Fig. 1. Methods used in the risk management process.

Another question asked was whether the risks are managed by an individual or department with multiple workers. It is clear from the picture that in most Czech enterprises the risk 
management process is carried out by a single employee and only in $17.9 \%$, enterprises in the Czech Republic have a department with more employees for risk management.

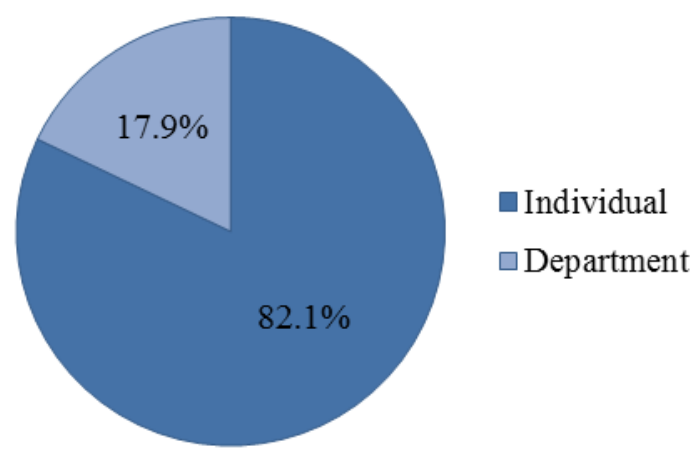

Fig. 2. Ensuring the risk management process.

The last question in the questionnaire survey was whether enterprises carry out the risk management process by their own employees, or hire outside workers and deal with this activity through outsourcing. The picture clearly shows that the risk management process in Czech enterprises is realized, in most cases, by the company's employees. Only $3.6 \%$ of Czech enterprises hire external workers.

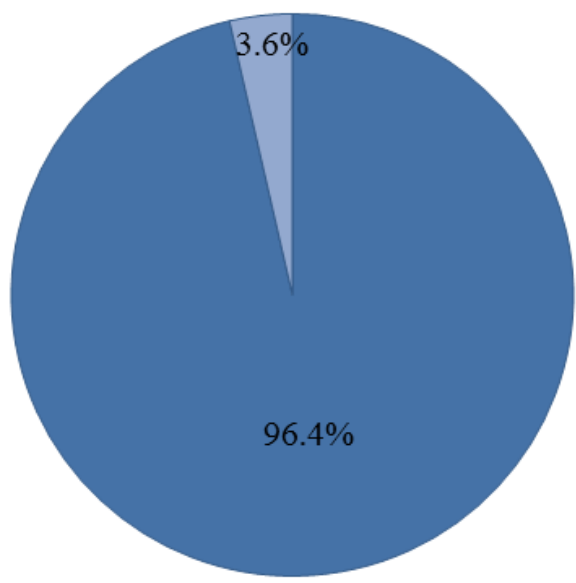

Employees $\square$ Contractor

Fig. 3. Implementation of risk management process.

\section{Conclusion}

The survey showed that the majority of the enterprises surveyed in the Czech Republic are national and rank among medium-sized enterprises by the number of employees. These companies prefer to implement the risk management process by their employees before hiring external staff. Most of these enterprises need only one employee who takes care of eliminating future risks in their enterprise, using the FMEA method, Scenario planning, What If Analysis and Check List. In addition to these methods, other risk analysis methods are used in enterprises.

The findings published in this article are the result of a questionnaire survey. The results are based on 28 surveyed companies in the Czech Republic, which were interviewed in the first quarter of 2019.

This paper was supported by the Integral Grant Agency, Tomas Bata University in Zlín IGA/FAME/2019/006, and by support research program of Tomas Bata University in Zlín (RVO).

\section{References}

1. K. McCormack, T. Wilkerson, D. Marrow, M. Davey, M. Shah, D. Yee. SCCRRT (2008)

2. T.-M. Choi, C.-H. Chiu, H.-K. Chan. TR, 90 (2016)

3. M. Kasperek, Planning and organization of logistic projects (UE, Katowice, 2006)

4. D. Celebi, D. Bayraktar, L. Bingöl. CIE., 58, 3, (2010)

5. I. Pisz. TLM. 4, (2011)

6. D. Cunderlik, D. Rybarova. Business risks. (Euba, Bratislava, 2002)

7. U. Rowbottom. SCP 6, 2 (2004)

8. R. Van Hoek. LRN, (2003)

9. C. S. Tang. IJPE 103, 2 (2006)

10. R. Bartosikova, J. Bilikova, P. Taraba. IBIMA (2014)

11. M. Abolghasemi, V. Khodakarami, H. Tehranifard. IJPM 8, 1 (2015)

12. Y. Petit. IJPM 30, 5 (2012)

13. Project Management Institute, $A$ guide to the project management body of knowledge, (PMI, 2008)

14. K. E. Papke-Shields, C. Beise, J. Quan. IJPM 28, 7 (2010)

15. J. Mu, G. Peng, D. L. MacLachlan. T, 29, 3 (2009)

16. S. Salomo, J. Weise, H. G. Gemünden. JPIM., 24, 4 (2007)

17. T. Raz, A. J. Shenhar, D. Dvir. R\&D Manag., 32, 2 (2002)

18. J. Dolezal, P. Machal, B. Lacko. Project management wia IPMA (Grada, Praha, 2012)

19. Ministry of Finance of the Czech Republic. Administrative Register of Businesses. [Internet]. Available from: http://wwwinfo.mfcr.cz/ares/okec/ares_okec.htm 1.cz. (2013) 